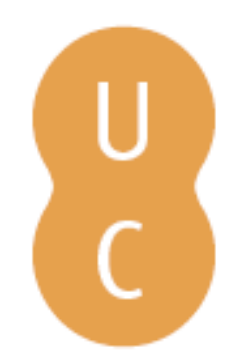

\title{
pommalina
}

\section{A Pedagogia da Palavra em Paulo Freire}

Autor(es):

Souza, Ester Maria de Figueiredo; Barreto, Denise Aparecida Brito; Barbosa, Márcia Regina

Publicado por: Imprensa da Universidade de Coimbra

URL

persistente:

URI:http://hdl.handle.net/10316.2/41295

DOI:

DOI:https://doi.org/10.14195/978-989-26-1326-0_6

Accessed : $\quad$ 26-Apr-2023 10:58:03

A navegação consulta e descarregamento dos títulos inseridos nas Bibliotecas Digitais UC Digitalis, UC Pombalina e UC Impactum, pressupõem a aceitação plena e sem reservas dos Termos e Condições de Uso destas Bibliotecas Digitais, disponíveis em https://digitalis.uc.pt/pt-pt/termos.

Conforme exposto nos referidos Termos e Condições de Uso, o descarregamento de títulos de acesso restrito requer uma licença válida de autorização devendo o utilizador aceder ao(s) documento(s) a partir de um endereço de IP da instituição detentora da supramencionada licença.

Ao utilizador é apenas permitido o descarregamento para uso pessoal, pelo que o emprego do(s) título(s) descarregado(s) para outro fim, designadamente comercial, carece de autorização do respetivo autor ou editor da obra.

Na medida em que todas as obras da UC Digitalis se encontram protegidas pelo Código do Direito de Autor e Direitos Conexos e demais legislação aplicável, toda a cópia, parcial ou total, deste documento, nos casos em que é legalmente admitida, deverá conter ou fazer-se acompanhar por este aviso.

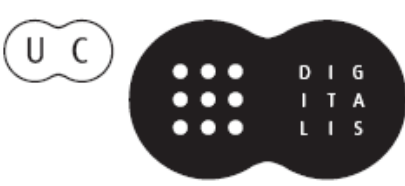




\title{
6. A PEDAGOGIA DA PALAVRA EM PAULO FREIRE
}

\author{
Ester Maria de Figueiredo Souza ${ }^{12}$ \\ Denise Aparecida Brito Barreto ${ }^{13}$ \\ Márcia Regina Barbosa ${ }^{14}$
}

\section{Resumo}

Nosso propósito é indiciar a noção de palavra, enquanto ato de interação entre sujeitos sociais, no pensamento freireano, a partir de nossa experiência enquanto professoras formadoras de professores na educação superior e em programas de educação de jovens e adultos. Para isso, incursionaremos a exploração da noção de palavra em Paulo Freire e em Mikhail Bakhtin, para afirmar que, na potência do pensamento freireano, a corresponsabilidade e dialogia se apresentam como condição para a instauração do diálogo e emancipação humana. Buscamos, assim, com esse texto, provocar para a necessidade de se compreender os processos educativos instaurados na prática com a linguagem, enquanto capacidade criadora para desvelar ideologias.

\footnotetext{
12 Professora da Universidade Estadual do Sudoeste da Bahia - UESB

13 Professora da Universidade Estadual do Sudoeste da Bahia - UESB

14 Professora da Universidade Federal de Pernambuco - UFPE
} 


\begin{abstract}
Our purpose in this paper is to reflect on the notion of word, as an interactive action between individuals, taking into account Freire's thinking. This reflection is based on our experience as teacher trainers in higher education and teachers in programs of youth and adult education. For this, we are going to explore the notion of word in the conceptualizations of Paulo Freire and Mikhail Bakhtin to say that, in the power of Freire's thinking, the co-responsibility and dialog are the conditions for the establishment of human emancipation. Therefore, this paper aims to raise awareness to the need to understand the educational processes initiated in practice through language, as a creative capacity to unveil ideologies.
\end{abstract}


Na realidade, não são palavras o que pronunciamos ou escutamos, mas verdades ou mentiras, coisas boas ou más, importantes ou triviais, agradáveis ou desagradáveis etc. A palavra está sempre carregada de um conteúdo ou de um sentido ideológico ou vivencial. É assim que compreendemos as palavras e somente reagimos àquelas que despertam em nós ressonâncias ideológicas ou concernentes à vida. (Bakhtin, 2009, p. 95)

\section{Introdução}

Para Paulo Freire o ensinar não existe sem o aprender e o aprender não existe sem o ensinar, logo é uma relação de reciprocidade. $\mathrm{O}$ ato de ensinar deve estar atrelado à capacidade de transpor barreiras para possibilitar o acesso ao conhecimento, da docência como feixe de saberes e experiências, e não só o domínio e conceitos e teorias. Enquanto professoras formadoras, filiadas e divulgadoras da pedagogia freireana em nossas aulas e cursos de formação, empreendemos nosso trabalho professando o vigor do pensamento freireano para refletir sobre experiências de aprendizagens, tanto na educação superior, como em programas de alfabetização de pessoas, jovens, adultas e idosas.

Essa nossa experiência envolve a dimensão ética, política, ideológica, estética e cultural de produzir o conhecimento, enquanto um dos processos sociais de emancipação humana. Ler e escrever para reconhecer-se enquanto sujeito social, pertencente a uma cultura e responsável por essa cultura e pela preservação da espécie.

Paulo Freire nos diz que quando o professor entra na sala de aula deve estar aberto às indagações, deve saber que ensinar não é transferir conhecimentos, mas criar possibilidades para a sua própria produção ou a sua construção, pois para ele é necessário aguçar 
a curiosidade dos alunos, devendo-se ensiná-los a serem críticos. Esses ensinamentos freireanos perpassam toda a sua obra e, em especial, a trilogia das Pedagogias, a do Oprimido, a da Esperança e a da Autonomia (Freire, 1981, 1992, 1996).

Para Bakhtin, a educação e o ensino não foram suas preocupações teóricas, contudo, seus escritos impõem um percurso por uma filosofia da linguagem, que concentra a noção de dialogia (Bakhtin, 2009), tão cara para a compreensão dos processos educativos, como de formação humana, liberdade individual e autonomia do sujeito social.

As reflexões da pedagogia freireana induzem à compreensão da sala de aula como um contexto favorecedor de interação, portanto, cabe ao professor valorizar o conhecimento trazido pelos alunos, buscando saber quais são as suas realidades, pois estas interferem em suas ações. Contudo, ainda, tem-se perpetuado as práticas de ensino bancárias, descontextualizadas.

O percurso de leitura da obra do Círculo de Bakhtin e, em especial, o livro Marxismo e Filosofia da Linguagem [grifos das autoras], induz para a extração da interação verbal como mola propulsora para interpretar os processos de construção de sentidos e a ideologia das relações sociais, por meio de produção e recepção de diferentes discursos que se veiculam na sociedade, na ininterrupta cadeia da comunicação humana.

Um desses espaços ideológicos é a universidade e seus cursos de formação. E, como professoras formadoras de professores e professoras, reconhecemos que a palavra não é outorga, mas gesto de autoria que introduz possibilidade de ampliar o diálogo e favorecer a tessitura composicional de domínio de conhecimentos e saberes experienciados pelos sujeitos em interação social.

Pautamos, assim, a interação verbal na sala de aula, como cenário discursivo para exposição das contribuições desses dois pensadores para a educação. 


\section{A potência do pensamento dialógico em Freire e Bakhtin}

A noção de sujeito, de concepção de mundo e de palavra enquanto linguagem são temas circundantes na obra de Paulo Freire ${ }^{15}$ e Mikhail Bakhtin ${ }^{16}$. Reflexões sobre as dimensões discursivas da linguagem e da própria existência estão presentes. A linguagem e a sua compreensão como ato de inconclusão, incompletude e inacabamento é tida como percurso de enunciação, dependente da ação do Outro para se constituir. Em Paulo Freire, os seus escritos da Pedagogia do Oprimido, Pedagogia da Esperança e Pedagogia da Autonomia enfatizam a abordagem de instauração do Outro para se humanizar o homem. Mikhail Bakhtin, principalmente no seu livro Marxismo e Filosofia da Linguagem, delimita a linguagem como processo de interação. A obra de Paulo Freire é inaugural e afirmativa de uma nova pedagogia emancipatória. A obra de Mikhail Bakhtin é pioneira no tratamento de linguagem enquanto produção histórica e processo interativo. Nessas produções dos dois autores, as dimensões ética, ideológica e constitutiva da linguagem se apresentam como inovadoras para fortalecer estudos e pesquisas no campo da formação de professores.

15 Paulo Freire foi o educador de Língua Portuguesa de maior renome mundial. Considerado por alguns, por exemplo Roger Garaudy, como 'o maior pedagogo do nosso tempo' foi, sem dúvida, quer a nível da produção teórica quer da intervenção prática, uns dos maiores pedagogos de todos os tempos. É uma referência obrigatória quando se fala da alfabetização, educação de adultos, educação popular ou comunitária. Pode-se estar de acordo ou em descordo com os seus pontos de vista; é, contudo, impossível ignorar a sua obra (...) Cerca de 30 universidades, de diferentes países, concederam-lhe doutoramentos Honoris Causa". (Apple, M. W. \& Nóvoa, António (Orgs). (1998). Paulo Freire: Política e Pedagogia. Porto: Porto Editora (pp 142-143).

$16 \mathrm{O}$ russo Mikhail Bakhtin foi um pensador, filósofo, teórico de artes e cultura. Lembrado como um dos maiores estudiosos da linguagem humana, suas obras influenciaram muitos pensadores de diversas áreas: crítica da religião, estruturalismo, semiótica, marxismo; e de diversos segmentos como psicologia, história, filosofia, linguística, crítica literária, entre outros. É relevante salientar que em muitos trabalhos atribuídos a Bakhtin há outras vozes e mãos que se complementam, especialmente os estudos desenvolvidos por ele e pelo seu grupo, que ficou conhecido como o Círculo de Bakhtin. O Círculo de Bakhtin (CB) foi uma escola do início do século 20 do pensamento russo, que foi centrada na obra de Mikhail Bakhtin. 
Uma dessas aplicações é a adoção de concepção de linguagem de cunho interacionista para a investigação da práxis pedagógica. McLaren (1999) ressalta que a potencialidade da obra freireana encontra-se em distintos campos de saber:

O que é notável na obra de Paulo Freire é que, ao mesmo tempo em que é nitidamente dirigida a educadores e alfabetizadores, continua a ser vigorosamente empregada por docentes em inúmeras disciplinas: teoria literária, composição, filosofia, etnografia, ciência política, sociologia, pedagogia, teologia etc. Ele deu à palavra "educador" um novo significado, flexionando o termo de modo a abraçar múltiplas perspectivas: intelectual fronteiriço, ativista social, pesquisador crítico, agente moral, filósofo radical, revolucionário político. Mais do que qualquer outro educador deste século, Freire conseguiu desenvolver uma pedagogia de resistência à opressão. Além disso, ele viveu aquilo que ensinava. Sua vida foi uma história de coragem, padecimento, perseverança e crença inquebrantável no poder do amor (Mclaren, 1999, p. 21).

Um dos aspectos que verticaliza uma teoria filosófica é a sua capacidade de gerar novas questões para provocar elucidações sobre os problemas do ser humano no mundo. A possibilidade criadora de uma filosofia é um dos aspectos que a define, como valoriza, e rica, conceitualmente, para sintonizar-se com produções de conhecimentos.

O diálogo é mais do que a comunicação face a face, é a recuperação de interditos e já ditos em outros tempos da comunicação humana, é mais do que um instrumento de comunicação, pois se constitui como exigência para se instaurar os processos educativos, visto que, como seres de linguagem, reconhecemos-nos como incompletos e dependentes da entrada no círculo de interação com o outro, para nos completarmos enquanto sujeito social. Esse 
enfoque dialético-dialógico do pensamento freireano, também explorado no pensamento bakhtiniano, inscreve a linguagem como o lugar de produção discursiva que acolhe, inclui posicionamentos ideológicos, trocas interativas e, também, acolhe o conflito como gerador da enunciação.

A centralidade do pensamento bakhtiniano voltava-se para as questões de importância na vida social, em geral, e criação artística, em particular, analisando o modo de produção e circulação da linguagem/palavra na sociedade..."o domínio ideológico coincide com o domínio dos signos: são mutuamente correspondentes. Ali onde o signo se encontra, encontra-se também o ideológico e tudo que é ideológico possui um valor semiótico" (Bakhtin, 2009, p.32). Três pontos parecem ser centrais nas discussões do Círculo de Bakhtin: compreensão de que a produção linguística é essencialmente dialógica, formada no processo de interação social, e que isso leva à interação de diferentes valores sociais sendo registrada reacentuando o discurso dos outros; entendimento de que a camada dirigente tentava postular um único discurso como exemplar, e as classes subalternas estavam inclinadas a subverter este encerramento monológico.

Há uma preocupação em não subjugar o acontecimento discursivo a juízos de valor pré-definidores do agir dos sujeitos, assim, a expressão verbal múltipla dos sujeitos sociais, o reconhecimento e valoração de suas culturas, como singularidades e marcas identitárias, reiteram a preocupação social com os excluídos, os menos favorecidos, os coletivos subalternos que estão no mundo para serem escutados e se colocarem no palco da história para romper com os processos de opressão e favorecer a apropriação, a consciência crítica, passando da consciência ingênua para a crítica, compreendendo esse processo e trânsito como formativo e auto formativo, possibilitado pelo uso da linguagem enquanto prática de interação verbal, desvelamento de ideologias e construtora de nova realidade. 
Em Pedagogia do Oprimido, Freire (1981) assentou que

A violência dos opressores, que os faz também desumanizados, não instaura uma outra vocação - a do ser menos. Como distorção do ser mais, o ser menos leva os oprimidos, cedo ou tarde, a lutar contra quem os fez menos. E esta luta somente tem sentido quando os oprimidos, ao buscarem recuperar sua humanidade, que é uma forma de criá-la, não se sentem idealistamente opressores, nem se tornam, de fato, opressores dos opressores, mas restauradores da humanidade em ambos (Freire, 1981, p.30).

Bakhtin (2009) nos diz que

Mas a palavra não é somente o signo mais puro, mais indicativo, é também um signo neutro. Cada um dos sistemas de signos é específico de algum campo particular de criação ideológica. Cada domínio possui seu próprio material ideológico e formula signos e símbolos que lhe são específicos e que não são aplicáveis a outros domínios. (Bakhtin, 2009, p.36)

Nesse percurso, as ideias de Paulo Freire, particularmente as apresentadas sobre a sua concepção de homem e educação na trilogia das pedagogias do Oprimido, da Esperança e da Autonomia reportam-nos ao diálogo com Mikhail Bakhtin (2009), no que concerne a compreensão da linguagem como processo histórico e de interação entre os homens.

Os dois autores são referenciados em estudos que englobam reflexões sobre os saberes docentes, sobre a produção ética, estética e história do conhecimento, sobre as concepções de linguagem e ensino, enfim, em diferentes aplicações teóricas e metodológicas no campo das ciências da linguagem e da educação. São singulares na sua produção e forjados em épocas e contextos 
culturais distintos. Os dois, nas suas trajetórias, carregam a inventividade do espírito científico, imbricado ao fazer ético da ciência, no suporte de que o homem modifica as suas condições materiais de existência.

Em ambos, a linguagem é compreendida a partir de sua natureza sócio-histórica e ideológica. Freire (1996) expõe que ensinar exige o reconhecimento de que a educação é ideológica:

Saber igualmente fundamental à prática educativa do professor ou da professora é o que diz respeito à força, à vezes maior do que pensamos, da ideologia. É o que nos adverte de suas manhas, das armadilhas em que nos faz cair. É que a ideologia tem que ver diretamente com a ocultação da verdade dos fatos, com o uso da linguagem para penumbrar ou opacizar a realidade ao mesmo tempo em que nos torna "míopes". (Freire, 1996, p.125).

A adoção dos pressupostos bakhtinianos e freireanos tem repercutido na compreensão de uma metodologia de ensino discursiva. Para essa metodologia confluem a apropriação da noção de dialogismo, de alteridade, de consciência material e produção sócio histórica da linguagem, quando do planejamento didático.

Se toda Pedagogia assenta suas bases em uma filosofia, "uma maneira de compreender, conceber algo" (Moura, 2012, p. 101), é possível crer que os conceitos fundantes da proposta de Paulo Freire configuram-se como esteio de uma filosofia ímpar no cenário da educação mundial, que em muito comungam com os pressupostos do respeito à cultura.

Embora muitos associem a pedagogia de Freire à alfabetização, é bem possível afirmar que seu legado vai muito além disso. Conforme Moura (2012), Freire não empreendeu seus primeiros esforços nesse campo, propriamente, mas na tentativa de se opor a uma educação domesticadora, normativa e que fosse capaz de 
transformar o homem-objeto, ingênuo, em homem-sujeito, dotado de voz e de um agir sobre o mundo.

Em tempos e espaços diversos, mas com a cronotopia necessária para situarem-se como expoentes de reflexão do seu tempo, para a vanguarda, as extrações dos autores referenciados corroboram para que possamos extrapolar a dimensão dialógica e corresponsável das enunciações didáticas da sala de aula, desconstroem perguntas diretas, do registrado nos manuais didáticos, para induzir professores e alunos a entoarem seus projetos de dizer, em corresponsabilidade e responsividade com o acontecimento discursivo que é o ensinar e aprender nas nossas salas de aula.

A contribuição de Freire é imperativa para a adoção de uma práxis democrática, na qual o reconhecimento da cultura, do diálogo, da escuta da palavra do outro e do espaço de dizer de minha palavra configura-se aspectos para aprimorar práticas de ensino e comungam com a necessidade do homem de, na condição de educando, "conhecer-se e conhecer também o outro."

Em Bakhtin e em Paulo Freire, no espaço da palavra como expressão de autoria, há a assunção de um posicionamento ativo do sujeito de reconhecer-se como pertencente ao mundo e com a consciência de que pode transformá-lo, “... de (re)fazer o mundo através da atitude de (re)criação da existência a partir do material que a vida coloca à disposição" (Moura, 2012, p. 16). Para Paulo Freire, o ser humano precisa reconhecer-se como incompleto, dependente do outro para se expressar, autônomo enquanto pessoa, mas pertencente a um determinado grupo social. É um ser herdeiro de experiências e trocas, mas é vívido e singular em seu percurso de formação. É, portanto, corresponsável, é não o responsável, para criar condições mais dignas, humanas e afetuosas de estar sendo no mundo.

A palavra só se constitui enquanto signo quando no percurso da enunciação, para se dotar de sentido e significações vincula-se a 
uma necessidade de dizer dos sujeitos. Isoladamente, a palavra não produz sentido. Há a necessidade da dialogia, pois toda orientação dialógica é natural das produções discursivas, se se fala se dirige a alguém, busca-se a réplica do outro, encontra-se com o dizer do outro, como nos assevera Bakhtin (1990)

A orientação dialógica é naturalmente um fenômeno próprio a todo o discurso.[...] Em todos os seus caminhos até o objeto, em todas as direções, o discurso se encontra com o discurso de outrem e não pode deixar de participar, com ele, de uma interação viva e tensa. Apenas o adão mítico que chegou com a primeira palavra num mundo virgem, ainda não desacreditado, somente este Adão podia realmente evitar por completo esta mútua orientação dialógica do discurso alheio para o objeto. Para o discurso humano, concreto e histórico, isso não é possível: só em certa medida e convencionalmente é que pode dele se afastar (Bakhtin, 1990, p.88).

Pela lente do olhar freireano, a palavra é geradora de conhecimento, aprendizagens e experiências. A palavra é matéria ideológica para desconstruir verdades estabelecidas e proporcionar a formação pela liberdade, a palavra é um gesto de tomada de consciência. Assim, para Paulo Freire a Educação é libertadora desde que atenda as classes populares, desde que se tenha consciência da opressão e de que só o próprio oprimido pode se libertar, por meio de lutas e embates que enriquecem o seu agir pessoal nas situações de resistência. De modo que as palavras/enunciados que nos constituem, enquanto sujeitos de luta social, somente se tornam significativas nas interações sociais em que os sentidos variam em função de sua inserção em contextos socioculturais e ideológicos distintos. Aqui fica evidente um diálogo teórico entre as teorias de Freire e de Bakhtin. 


\section{Conclusões}

A busca de interseções entre o pensamento freireano e bakhtiniano tem nos motivado para o planejamento de nossas atividades de ensino e formação de professores. A inserção da noção de palavra, em compasso com as reflexões sobre o percurso de constituição da docência, revela-nos como uma de suas compreensões, que essa constituição é um percurso em devir [grifo das autoras], em trajetórias que recuperam experiências de acertos e erros, pelas trocas e coletividades enunciadas nos espaços de formação.

Essa compreensão recupera a noção de palavra como fonte do próprio diálogo, relacionada à compreensão da história como possibilidade, como acontecimento que produz subjetividades e que se opõe à visão fatalista da realidade. Procuramos utopias, para denunciar organizações de ensino que se orientam pela produtividade, pela lógica do mercado global e que negam movimentos dialógicos de constituição de autoria docentes, valorizando o cotidiano e a cultura escolar como seus tempos e espaços de formação. A teoria brota da imersão natural do sujeito na sua própria realidade e requer um exercício de reflexão e autorreflexão para emergir, o que é possível pelas trocas e apropriações das palavras enquanto signo ideológico. Essa acepção se apresenta tanto na obra freireana, como bakhtiniana. Tal concepção nos faz assumir que é possível perspectivar da pedagogia emancipatória de Paulo Freire, de sua denúncia de uma educação bancária para uma educação problematizadora, uma pedagogia do ato responsivo, uma pedagogia da palavra que elege a palavra como arena de luta e conflito, mas também abrigo para realizarmos sonhos compartilhados na seara da educação nas classes populares.

Necessária a afirmação de que essas prévias conclusões são reflexões e não têm a pretensão de serem exaustivas. Espera-se que sejam entendidas como convite para provocações dialógicas, abertura de trilhas para enveredar pelas contribuições dos autores listados. 
Não é exagero afirmar que Paulo Freire elege a palavra como "método" na sala de aula, desde a sua experiência em Angicos, no sertão do Brasil, e permanece atual a sua capacidade criadora para gerar novas metodologias de ensino e reflexões sobe a emancipação humana nesse mundo tão desigual.

\section{Referências bibliográficas}

Bakhtin, M. (1990). Questões de literatura e de estética. A teoria do romance. São Paulo: Hucitec.

Bakhtin, Mikhail \& Volochínov, V. N.). (2009). Marxismo e filosofia da linguagem. Problemas fundamentais do método sociológico na ciência da linguagem (13 ${ }^{\mathrm{a}}$ ed.). São: Paulo: Hucitec.

Freire, P. (1981). Pedagogia do Oprimido. (9 ${ }^{\mathrm{a}}$ ed.). Rio de Janeiro: Paz e Terra.

Freire, P. (1992). Pedagogia da Esperança: um reencontro com a Pedagogia do Oprimido. ( $8^{\text {a }}$ ed.). Rio de Janeiro: Paz e Terra.

Freire, P. (1996). Pedagogia da autonomia: saberes necessários à prática educativa.

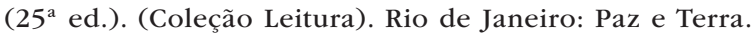

Mclaren, P. (1999). Utopias Provisórias. As pedagogias críticas num cenário pós-colonial. Petrópolis: Editora Vozes.

Moura, E. M. (2012). Leitura em Bakbtin e Paulo Freire: palavras e mundos. São Paulo: Pedro e João Editores. 